\title{
Utilização de Nanopartículas no Tratamento do Câncer: Aspectos Gerais, Mecanismos de Ação Antineoplásicos e Aplicabilidades Tumorais
}

doi: https://doi.org/10.32635/2176-9745.RBC.2019v65n4.400

\author{
Nanoparticles in Cancer Treatment: General Aspects, Antineoplastic Mechanisms of Action and Tumor Applications \\ Nanopartículas en el Tratamiento del Cáncer: Aspectos Generales, Mecanismos de Acción Antineoplásicos y Aplicaciones \\ Tumorales
}

Juliana Carvalho Lopes'; Maria Lúcia Pereira Torres²

Resumo

Introduçáo: Os avanços tecnológicos das últimas décadas levaram ao desenvolvimento de abordagens terapêuticas na medicina em uma nova escala de aplicaçôes moleculares nanométricas, permitindo o estabelecimento de novas terapias como a nanoterapia. O uso de nanopartículas implica inúmeras oportunidades e também grandes desafios para a aplicação humana, esse uso requer uma compreensão minuciosa da biocompatibilidade e da farmacodinâmica das moléculas. No câncer, as nanopartículas atuam principalmente na forma ativa, que se caracteriza pela utilizaçáo de ligantes ou anticorpos em suas superfícies onde se ligam a determinadas células, e, na passiva, onde as partículas se acumulam nos tecidos tumorais em razão das largas frenestraçóes dos endotélios tumorais. Objetivo: Abordar as principais propriedades das nanopartículas de proteína, metal, polímero e lipídio, suas estruturas e utilizaçôes contra células cancerígenas específicas e as vantagens e desvantagens do seu uso. Método: Selecionar artigos com estudos sobre nanopartículas entre os anos de 2010 a 2018 nos bancos de dados PubMed e SciELO por meio de revisão integrativa da literatura. Resultados: As nanopartículas apresentam diferentes mecanismos de ação e podem obter resultados mais favoráveis de acordo com sua estrutura química. Conclusáo: Concluiu-se com esta revisão que determinadas nanopartículas apresentam funcionalidades que potencializam os efeitos anticancerígenos dos fármacos antineoplásicos e surgem como uma nova abordagem para tratamentos contra o câncer.

Palavras-chave: Nanopartículas/administração \& dosagem; Nanopartículas/uso terapêutico; Neoplasias; Antineoplásicos.

\begin{abstract}
Introduction: Technological advances in recent decades have led to the development of therapeutic approaches in medicine on a new scale of nanometric molecular applications, allowing the establishment of new therapies such as nanotherapy. The use of nanoparticles entails numerous opportunities as well as major challenges for human application where use requires a thorough understanding of the biocompatibility and pharmacodynamics of molecules. In cancer, nanoparticles act mainly in the active forms that are characterized by the use of ligands or antibodies on their surfaces where they bind to certain cells, and in the passive form, where particles accumulate in tumor tissues due to the large fractions of tumor endothelium. Objective: To address the main properties of protein, metal, polymer and lipid nanoparticles, their structures and uses against specific cancer cells and the advantages and disadvantages of their use. Method: Selection of articles with studies on nanoparticles from 2010 to 2018 in the PubMed and SciELO databases through narrative review of the literature. Results: Nanoparticles have different mechanisms of action and may obtain more favorable results according to their chemical structure. Conclusion: Based in this review, it was concluded that certain nanoparticles have functionalities that enhance the anticancer effects of antineoplastic drugs and emerge as a new approach for cancer treatments.

Key words: Nanoparticles/administration \& dosage; Nanoparticles/ therapeutic use; Neoplasms; Antineoplastic Agents.
\end{abstract}

Resumen

Introducción: Los avances tecnológicos en las últimas décadas han llevado al desarrollo de enfoques terapéuticos en medicina en una nueva escala de aplicaciones moleculares nanométricas, lo que permite el establecimiento de nuevas terapias como la nanoterapia. El uso de nanopartículas conlleva numerosas oportunidades, así como desafíos importantes para la aplicación en humanos, este uso requiere un conocimiento profundo de la biocompatibilidad y farmacodinámica de las moléculas. En el cáncer, las nanopartículas actúan principalmente en las formas activas que se caracterizan por el uso de ligandos o anticuerpos en sus superficies donde se unen a ciertas células, y el pasivo, donde las partículas se acumulan en los tejidos tumorales debido a las grandes fracciones del endotelio tumoral. Objetivo: Abordar las principales propiedades de las nanopartículas de proteínas, metales, polímeros y lípidos, sus estructuras y usos contra células cancerosas específicas y las ventajas y desventajas de su uso. Método: Seleccionar artículos con estudios sobre nanopartículas de 2010 a 2018 en las bases de datos PubMed y SciELO, a través de revisión de la literatura integrativa. Resultados: Las nanopartículas tienen diferentes mecanismos de acción y pueden obtener resultados más favorables según su estructura química. Conclusión: Concluido con esta revisión que ciertas nanopartículas tienen funcionalidades que mejoran los efectos anticancerígenos de los fármacos antineoplásicos y emergen como un nuevo enfoque para los tratamientos contra el cáncer.

Palabras clave: Nanopartículas/administración \& dosificación; Nanopartículas/uso terapéutico; Neoplasias; Antineoplásicos.

\footnotetext{
${ }^{1}$ Curso de Biomedicina do Centro Universitário Christus. Fortaleza, (CE), Brasil. Orcid iD: https://orcid.org/0000-0003-4523-8461 ${ }^{2}$ Curso de Biomedicina do Centro Universitário Christus. Fortaleza, (CE), Brasil. Orcid iD: https://orcid.org/0000-0003-0153-7558 Endereço para correspondência: Juliana Carvalho Lopes. Rua Padre Mororó, 795 - Casa 14 - Centro. Fortaleza (CE), Brasil. CEP 60015-220. E-mail: julianacarvalho.121@hotmail.com
} 


\section{INTRODUÇÃO}

A nanotecnologia estuda a produção de partículas em escala nanométrica, de 1 a $100 \mathrm{~nm}$, que podem ser aplicadas em várias áreas, como na indústria tecnológica ou na medicina, e chama a atenção dos cientistas pelo seu bom desempenho em ensaios tanto in vivo como in vitro ${ }^{1}$. O primeiro a citar a nanotecnologia como uma ferramenta otimizada foi o físico Richard Feynman, demonstrando alguns métodos que auxiliavam no desenvolvimento de moléculas extremamente pequenas até o tamanho que fosse necessário ${ }^{2}$.

As nanomoléculas podem ser produzidas a partir de muitos materiais e em variados tamanhos que, dependendo de suas formas, são encontradas em 0D, $1 \mathrm{D}, 2 \mathrm{D}$ ou $3 \mathrm{D}^{3}$. Por meio da possibilidade de moldar o seu tamanho e sua forma, essas partículas são de extrema utilidade no tratamento de enfermidades, pela capacidade de carrear drogas, ser sinalizador tumoral, e ainda auxiliar no diagnóstico de doenças, e se configuram uma nova terapia voltada para uso das nanopartículas (NP) no meio médico, a nanoterapia 4 .

Em virtude da heterogeneidade do câncer, novas estratégias que abordam os processos de morte neoplásica estâo sendo avaliadas ${ }^{5}$, abrindo espaço para a utilização das NP que amenizam efeitos colaterais disseminados das quimioterapias ${ }^{6}$ por causa da sua especificidade direcionada ao tecido tumoral e da sua maior absorção ${ }^{7,8}$. As NP são moldadas para conseguirem se depositar em locais de inflamação ou tumorais por causa do afastamento das células endoteliais, característico do tecido neoplásico?. O objetivo geral deste trabalho é avaliar as principais propriedades das NP de proteína, metal, polímero e lipídio, suas estruturas, utilizaçôes e suas limitaçōes e vantagens contra células cancerígenas.

\section{MÉTODO}

Para compor esta revisão integrativa da literatura, foi realizada uma busca nos presentes bancos de dados PubMed e SciELO, entre os anos de 2010 a 2018, por haver uma crescente evolução das pesquisas com nanoterapia durantes esses anos. Para refinar as buscas, utilizaram-se os descritores nanoparticle; cancer, anticancer, nanopartículas, câncer e anticâncer, sem a utilização dos descritores boleanos (AND, OR, AND NOT). Entre os critérios da seleção da literatura, estavam artigos em inglês e português, artigos que apresentavam experimentos in vivo e in vitro com NP, artigos que abordavam NP proteicas, metálicas, lipídicas e poliméricas por serem as principais NP encontradas em pesquisa atualmente e artigos que envolviam nanomoléculas carreadoras ou não de fármacos. Para a seleção das principais NP metálicas, filtraram-se as NP mais frequentes nos bancos de dados onde foi realizada a busca bibliográfica. Após leitura dos artigos encontrados, apenas as NP metálicas de zinco, platina e prata foram selecionadas para compor esta revisão na categoria de metal.

Foram encontrados 1.219 artigos envolvendo os descritores utilizados para a busca nos dois bancos de dados, dos quais, apenas 261 se encaixaram nos critérios de inclusão. Excluíram-se as pesquisas não específicas envolvendo células neoplásicas e aplicaram-se os seguintes critérios de exclusão, que foram produçôes que envolviam apenas artigos com experimentos de produção de NP, artigos que utilizavam NP como marcador tumoral indiretamente, artigos que apresentavam apenas ensaios de citotóxidade celular sem utilizar experimento com células neoplásicas malignas e artigos que não informavam o tempo de execução do experimento realizado. Após leitura detalhada e aplicação dos critérios de exclusão, 65 artigos foram selecionados para compor a revisão bibliográfica. Para melhor abordagem desta revisão, cinco literaturas complementares de periódicos e livros envolvendo fisiologia do câncer e fabricação de NP foram adicionadas ao compilado bibliográfico.

\section{RESULTADOS E DISCUSSÃO}

As NP podem ser produzidas a partir de diversos materiais. Metais, lipídios, proteínas, lipossomos ou polímeros são algumas das NP encontradas hoje nas principais linhas de pesquisa no tratamento do câncer ${ }^{6}$.

O endotélio vascular normal possui cerca de 5 a 10 $n m$ de distância entre suas fenestraçóes (aberturas entre as células), enquanto os novos vasos, que surgem por causa da angiogênese tumoral ${ }^{10} \mathrm{e}$ da alta necessidade de nutriçãoo ${ }^{11}$, possuem tamanhos entre 100 a $780 \mathrm{~nm}^{10}$. Esse tipo de utilização das NP é conhecido como Enhanced Permeability and Retection (EPR) ou vetorização passiva voltada para o acúmulo dessas NP no endotélio neoplásico?.

Além do mecanismo de acumulação, existe outra técnica que envolve a administraçáo das NP, a vetorização ativa. Nesse processo, ligantes projetados na superfície das NP irão interagir especificamente com as células do câncer e seus receptores. Esses ligantes podem ser anticorpos monoclonais, aptâmeros ou peptídeos ${ }^{10}$. Após a NP ser absorvida pela célula, por meio da formaçáo de micropinossoma e endossomo ${ }^{12}$, o endossoma é fundido com o lisossomo, que ficará responsável por degradar a partícula absorvida ${ }^{13}$. Muitos fármacos utilizam da via endossomal para chegarem ao citosol e iniciarem seus mecanismos de ação ${ }^{14}$. 
A quantidade de metais utilizados na indústria farmacêutica como agente antimicrobiano ${ }^{15} \mathrm{e}$ antineoplásico é vasta ${ }^{16}$. Metais como a prata, ouro, platina e ferro compóem a lista dos principais metais usados em experimentos na terapia do câncer ${ }^{17}$, cuja importância de agentes metálicos para a nanomedicina é atrativa para os pesquisadores. Podendo ser moldada em vários tamanhos e de variadas formas, as partículas metálicas apresentam aspectos farmacodinâmicos e farmacocinéticos que favorecem a indução da célula cancerígena à morte ${ }^{18}$.

Em geral, o mecanismo que os metais usam para gerar morte celular é principalmente a indução de apoptose ou necrose pela geração de espécies reativas de oxigênio (ERO). As ERO são as principais moléculas responsáveis por danificar a estrutura da membrana celular por meio de peroxidação e desnaturação proteica, levando ocasionalmente a célula à morte ${ }^{17}$. A morte celular causada pela geração de ERO é específica das NP de metais. O excesso de produção de ERO pode ser maléfico para a célula, sendo responsável também por danos à dupla-fita de DNA ${ }^{19}$.

A morte celular por apoptose é um processo natural regulado positivamente por genes supressores tumorais como o p53, que induz outros genes pró-apoptóticos, como receptores de morte celular e genes da família BCL-2, que liberam moléculas apoptóticas para o citosol, acelerando o processo de morte celular ${ }^{20}$. A principal fonte produtora de ERO dentro da célula é a mitocôndria, em razão dos seus processos químicos de geração de energia. Quando as ERO se excedem ou escapam da mitocôndria, essas moléculas invadem o citosol conseguindo destruir estruturas moleculares maiores, como o DNA, ou causam estresse oxidativo por lesão da membrana plasmática ${ }^{16}$, tornando as ERO um importante mecanismo contra células neoplásicas ${ }^{19}$. Após a lesão genética, os genes pró- -apoptóticos são ativados, induzindo a célula à morte pelas vias apoptóticas ou pela autofagia ${ }^{16}$.

$\mathrm{O}$ zinco é um metal encontrado em vários campos da indústria, como em cosméticos, produtos dentais, plásticos etc. Recentemente, com o avanço da nanomedicina, tornou-se um importante componente utilizado para a produção de NP. A eficácia das moléculas de zinco contra células de carcinoma hepatocelular (HepG2), câncer de próstata e câncer de ovário tem sido relatada em vários estudos experimentais ${ }^{21}$.

O zinco é um metal reconhecido como seguro pela Food and Drug Administration (FDA) e apresenta baixos índices de toxicidade em relação ao seu tamanho, aspecto que necessita de atençáo para não tornar-se um carreador perigoso e instável com baixa biocompatibilidade ${ }^{22}$. A molécula de zinco leva a célula cancerígena à morte a partir do estresse oxidativo ocasionado pelas ERO, causando quebra de material genético e sucessivamente morte celular. Moléculas pró-inflamatórias como o interferon C, interleucina 2 (IL-2), ou o fator de necrose tumoral alfa são observadas em altos níveis ao se utilizar NP de zinco ${ }^{16}$.

Estudos utilizando NP de zinco relataram alta seletividade para células cancerígenas em comparação com outras terapias anticâncer ${ }^{16}$. No estudo apresentado por Chung et al. ${ }^{23}$, por exemplo, as NP de zinco são utilizadas para tratar células de HepG2 em diferentes dosagens e concentraçóes que alternaram entre $50 \mathrm{mg}$ e $500 \mathrm{mg}$ (Tabela 1).

$\mathrm{Na}$ dosagem mais alta de $500 \mathrm{mg}$, foi observado um índice de morte celular de aproximadamente $86 \%$ em células de HepG2 nas primeiras 24 horas, concluindo que a morte celular é principalmente dose-dependente. Neste estudo, também foram medidos os índices de capases presentes no meio de cultura, nas diferentes concentraçóes de NP de zinco, indicando o aumento progressivo ao

Tabela 1. Experimentos envolvendo nanopartículas à base de metais

\begin{tabular}{|c|c|c|c|c|c|c|}
\hline & Autor/ano & $\begin{array}{l}\text { In vivo/ } \\
\text { in vitro }\end{array}$ & $\begin{array}{c}\text { Tipo de célula } \\
\text { tumoral }\end{array}$ & Linhagem & Concentração & $\begin{array}{l}\text { Redução da } \\
\text { viabilidade } \\
\text { (\%) após } 24 \text { h }\end{array}$ \\
\hline \multirow{3}{*}{ Zinco } & Wang et al., 2014 & In vitro & Oral & CAL-27 & $100 \mathrm{ug} / \mathrm{ml}$ & $*>80 \%$ \\
\hline & Bai et al., 2017 & In vitro & Ovário & SKOV3 & $30 \mathrm{mg} / \mathrm{ml}$ & $*>70 \%$ \\
\hline & Arooj et al., 2015 & In vitro & Melanoma & $\mathrm{Ht} 144$ & $100 \mathrm{ug} / \mathrm{ml}$ & $*>80 \%$ \\
\hline \multirow{3}{*}{ Prata } & Choi et al., 2016 & In vitro & Ovário & 2780 & $1.000 \mathrm{ug} / \mathrm{ml}$ & $60 \%$ \\
\hline & Han et al., 2017 & In vitro & Germinativa & F9 & $50 \mathrm{ug} / \mathrm{ml}$ & $60 \%$ \\
\hline & $\begin{array}{l}\text { Baharara et al., } \\
2018\end{array}$ & In vitro & Cervical & HeLa & $60 \mathrm{ug} / \mathrm{ml}$ & $80 \%$ \\
\hline
\end{tabular}

Legenda: ${ }^{*}>=$ morte celular maior ou acima de. 
longo da dosagem, que contrasta com a morte celular de HepG2.

Outro estudo que pode constatar a efetividade das NP de zinco é o experimento realizado por Bai et al. ${ }^{16}$. Neste estudo, as NP de dióxido de zinco $(\mathrm{ZnO})$ foram utilizadas para tratar células cancerígenas de ovário em concentraçóes de até $30 \mu \mathrm{g} / \mathrm{ml}$ durante 12 e 24 horas. Após 24 horas, Bai et al. ${ }^{16}$ observaram que houve uma redução de quase $70 \%$ de células cancerígenas quando estas eram expostas a $30 \mu \mathrm{g} / \mathrm{ml}$ de $\mathrm{ZnO}$ NP (Tabela 1).

A prata é bastante comercializada e está presente em muitos produtos como máquinas industriais, próteses e instrumentos cirúrgicos ${ }^{24}$. Por muito tempo, as NP de prata foram usadas em eletrônicos e energia, mas recentemente têm chamado a atençáo por apresentar propriedades apoptóticas ${ }^{25}$.

Os íons de prata são capazes de induzir citotoxicidade celular por intermédio do aumento da instabilidade de sódio e potássio nos canais iônicos da membrana celular, que desestabiliza a mitocôndria e libera ERO, levando a célula à morte ${ }^{19}$. Apesar da sua eficiência em geração de ERO e morte tumoral, no estudo feito por Bhanumathi et al. ${ }^{26}$, foram observados leves efeitos citotóxicos em tecidos saudáveis de camundongos que teriam sido expostos à NP de prata no coração, rim, cérebro e pulmão.

Estudos mostram que células tumorais de células epiteliais alveolares humanas (A549), células neuroendócrinas e células de ovário já foram encontradas em experimentos com prata ${ }^{19}$, além de já ter sido comprovada sua efetividade contra células de leucemia mieloide e câncer de mama ${ }^{27}$. Na Tabela 1 , são apresentados alguns experimentos envolvendo NP de prata e seus respectivos índices de diminuição tumoral.

Nos estudos de Bahahara et al..$^{28}$ e He et al. ${ }^{29}$, as NP de prata foram produzidas a partir de extratos naturais de plantas e frutas, utilizando o princípio alternativo da Green Technology ou Tecnologia Ambiental, uma alternativa que se utiliza apenas compostos naturais ${ }^{9}$. No estudo de $\mathrm{He}$ et al. ${ }^{29}$, o extrato da Dimocarpus longan, uma tradicional fruta chinesa, foi utilizada como composto redutor de prata em virtude da sua composição fenólica. He et al. ${ }^{29}$ observaram que, quando expostas a células cancerígenas de pulmão, as NP de prata feitas a partir de Dimocarpus longan conseguiram inibir em até $90 \%$ a porcentagem de crescimento tumoral. Já no estudo de Bahahara et al. ${ }^{28}$ (Tabela 1), as NP de prata não só foram reduzidas com o extrato da planta Zataria multiflora, como também receberam compostos oxidantes dessa planta, o que potencializou o efeito tóxico já presente em NP de prata, mostrando seu efeito apoptóticos em células tumorais.

Em apenas 24 horas, a NP de prata foi capaz de reduzir em até $80 \%$ o crescimento de células cancerígenas cervicais em uma concentração de $60 \mu \mathrm{g} / \mathrm{ml}$, demonstrando a eficiência oxidante e apoptótica de extratos naturais também encontrada no estudo de $\mathrm{He}$ et al. ${ }^{29}$.

Choi et al. ${ }^{20}$ também utilizaram Green Technology para produzir NP de prata a partir de culturas de E. coli. Em 24 horas, a viabilidade celular foi reduzida em $50 \%$, e também foram quantificados os níveis de lactato desidrogenase (LDH) prominina-1 e outros marcadores de lesão celular pela imunofluorescência.

Em contraste com os redutores naturais utilizados nos estudos de Bahahara et al. ${ }^{28}$ e He et al..$^{29}$, o experimento apresentado por Bhanumathi et al. ${ }^{26}$ utiliza o composto químico boro-hidreto de sódio $\left(\mathrm{NaBH}_{4}\right)$ como agente redutor de NP de prata. No estudo de Bhanumathi et al. ${ }^{26}$, as NP de prata carrearam ácido fólico e berberina em seu interior, causando uma diminuição de mais de $80 \%$ na viabilidade celular de células cancerígenas mamarias. Outro importante dado é demonstrado no estudo de Bhanumathi et al. ${ }^{26}$, que expuseram NP de prata conjugadas com ácido fólico e beberina a células saudáveis da mama, sendo observado que o efeito tóxico de viabilidade celular em relação a essas células foi cerca de $20 \%$ em 48 horas, concluindo que células normais de mama não seriam gravemente afetadas quando expostas ao conjugado de NP de prata.

As NP à base de metais, principalmente de zinco, apresentam significantes efeitos geradores de autofagia que facilitam e potencializam os efeitos causados pela ERO e, consequentemente, induzem com maior facilidade a morte de células cancerígenas, também causada pela flexibilidade das moléculas de zinco, o que as tornam ótimas moléculas carreadoras também ${ }^{21,30,31}$.

$\mathrm{Na}$ nanoterapia, a platina apresenta variadas formas químicas e conjugadas. As drogas cisplatina e carboplatina são dois exemplos de variaçóes à base de platina em estudos $^{32}$. Essas drogas são aplicadas para tratar os cânceres de cabeça e pescoço, ovário e pulmão ${ }^{33}$.

A cisplatina ou cis-diaminodicloroplatina ${ }^{34}$ é uma droga antineoplásica utilizada para tratar cânceres de ovário, testículo e células do sistema periférico humano ${ }^{35}$. $\mathrm{O}$ mecanismo de ação da cisplatina está relacionado à quebra do DNA. A droga é capaz de anular os processos biológicos de transcrição e tradução, levando assim a célula à morte por lesão genética ${ }^{36}$. Entretanto, a cisplatina encontra muitas barreiras biológicas, como rápida eliminação, resistência à droga, graves efeitos tóxicos nos rins, cérebro, fígado e principalmente em células da medula óssea ${ }^{34}$.

Apesar dos aspectos tóxicos da cisplatina, alguns estudos náo encontram citotoxicidade elevada em determinadas células. No experimento realizado por Bendale et al. ${ }^{37}$, as NP de platina não mostraram 
efeitos citotóxicos em células mononucleares do sangue periférico. Porém, quando postas em contato com células tumorais do câncer de pulmão, pâncreas e ovário, as NP conseguiram induzi-las à morte celular, constatando seu efeito citotóxico específico para células tumorais, principalmente na fase G1 do ciclo celular.

A carboplatina, composta por cis-diamina (1,1-ciclobutanodicarboxilato) platina, foi desenvolvida para substituir a cisplatina ${ }^{33}$ principalmente por ser capaz de ser administrada em doses elevadas ${ }^{38}$, tornando-se mais recomendada do que a cisplatina, e apresentando menor toxicidade e maior biocompatibilidade. Apesar das suas peculiaridades não tóxicas, a carboplatina apresenta baixa absorção tumoral, o que a torna uma droga com eficácia reduzida $^{33}$. Essa droga apresentou ineficiência contra células de câncer de pescoço, germinativa testicular e carcinoma de células escamosas ${ }^{38}$.

As NP de proteínas demonstram como uma de suas grandes vantagens a biodegradabilidade, característica importante que não está presente nos metais, pela tecnologia ambiental ${ }^{9}$. As NP de proteínas são biocompatíveis, facilmente degradadas pelo organismo e dispóem de facilidade para se moldar e adicionar ligantes em suas superfícies ${ }^{39}$.

As NP proteicas possuem melhor compatibilidade com o corpo humano por serem produzidas a partir de uma proteína já existente como a gelatina ou a albumina ${ }^{9}$. A NP de albumina ou NAB, como também é conhecida, é feita a partir de uma droga encapsulada dentro da molécula de albumina, apresentando grande importância para a nanotecnologia pelo seu poder de retenção tumoral nos vasos que irrigam o tecido cancerígeno ${ }^{40}$. A principal aplicação das NP de proteína no tratamento anticancerígeno é sua capacidade carreadora de fármacos que dribla o sistema imunológico fazendo com que o fármaco carreado pela NP de proteína permaneça na corrente sanguínea por mais tempo ${ }^{39}$.

A NP de proteína pode também ser utilizada junto com outras NP de composiçóes químicas diferentes, como no estudo apresentado por Azizi et al..$^{41}$. Nesse experimento, as NP de albumina foram utilizadas para carrear NP de prata. $\mathrm{O}$ índice de células cancerígenas de mama mortas por esse complexo chegou a quase $70 \%$ com NP de $100 \mu \mathrm{M}$ de tamanho. As NP de albumina são comumente estudadas e já se encontram no mercado farmacêutico como uma NP à base de albumina que carrega o antineoplásico placlitaxel em seu interior ${ }^{9}$. No estudo de Lee et al. ${ }^{42}$, o placlitaxel foi internalizado em uma NP de albumina revestida com polietilenoglicol (PEG) para tratar um tumor xenográfico de células mamárias. Lee et al. ${ }^{42}$ observaram que, em uma concentração de $100 \mathrm{~nm}$, a viabilidade celular tumoral foi reduzida mais de $50 \%$ em apenas 24 horas.
Apesar de a albumina ser a principal proteína utilizada como nanocarreador, não é a única. Alguns estudos utilizam outras NP como proteínas de leite de camelo ${ }^{43}$ gelatina, elastina e até proteínas da soja ${ }^{39}$.

As NP lipídicas, que englobam as formas lipossomais e micelares, apresentam-se atóxicas e biocompatíveis dentro do corpo humano ${ }^{10}$. Alguns estudos relatam a facilidade das NP lipídicas de serem moldadas em formas sólidas e, assim, se tornarem mais suscetíveis a encapsulamento de fármacos em seu interior ${ }^{44}$. As NP lipídicas possuem uma entrega do fármaco mais eficiente nos sítios de ação nos tratamentos contra o câncer, em razão da sua estrutura hidrofílica, com somente uma camada de fosfolipídio ${ }^{10}$.

A forma lipossomal das NP lipídicas é uma categoria de carreador de fármacos quimioterápicos. Atualmente, as NP lipossomais apresentam dois fármacos em estudo, a citarabina e o irinotecan ${ }^{45}$. Com a sua estrutura fosfolipídica, os lipossomos possibilitam o carreamento de fármacos hidrofílicos e lipofílicos ao mesmo tempo, além de apresentarem maior fluidez comparadas com as NP lipídicas ${ }^{10}$. As micelas também fazem parte das NP lipídicas. Essas NP apresentam camadas de copolímeros anfifílicos, que se dispóem ao redor de uma estrutura nuclear hidrofóbica, na qual são incorporados os fármacos com baixa solubilidade em água que serão encapsulados ${ }^{45}$.

Apesar dos seus benefícios, alguns obstáculos importantes são enfrentados por NP lipídicas. A fácil degradaçáo pelo $\mathrm{PH}$ estomacal e pelas enzimas do intestino, por exemplo, diminuem as habilidades de armazenamento dessas partículas. Outros problemas frequentes são a instabilidade em meio lipídico, e a toxicidade de compostos utilizados na fabricação dessas $\mathrm{NP}^{46}$. No Quadro 1, são mostradas as principais vantagens e desvantagens das NP biodegradáveis (proteínas, polímeros e lipídios) e de metais.

A atribuição de polímeros como NP surgiu a partir da necessidade de novas formas de fabricação de NP que não fossem tóxicas ao meio ambiente. Essas moléculas à base de polímeros sintéticos são biocompatíveis, apresentam ótima absorção tecidual e não são tóxicas para o organismo, o que faz dessa categoria um dos subtipos de NP utilizadas nas mais recentes pesquisas com entrega de fármacos ${ }^{47}$.

Existem vários tipos de formulações sintéticas de polímeros que diferem de acordo com a finalidade terapêutica que se deseja obter. Os polímeros mais usados como carreadores de fármacos são o poliácido lático (PLA) e o $\mathrm{PEG}^{48}$. O PLA é um polímero formado a partir de uma copolimerizaçáo de dois monômeros, o ácido glicólico e o ácido lático, que são facilmente degradados pelo metabolismo humano pelo ciclo de Krebs ${ }^{49}$. PLA está presente em sacolas plásticas, embalagens ou até mesmo em $\operatorname{cosméticos}^{47}$. 
Quadro 1. Vantagens e desvantagens das categorias de nanopartículas de metais e biocompatíveis

\begin{tabular}{|c|c|c|}
\hline & Metálicas & Poliméricas, lipídicas e proteicas \\
\hline Vantagens & $\begin{array}{l}\text { - Podem gerar espécies reativas de } \\
\text { oxigênio } \\
\text { - São facilmente moldadas e } \\
\text { produzidas } \\
\text { - Podem ser produzidas por Green } \\
\text { Technolog }\end{array}$ & $\begin{array}{l}\text { - Normalmente não utilizam de reagente tóxico } \\
\text { para o meio ambiente } \\
\text { - Podem carrear dois fármacos ao mesmo tempo } \\
\text { em sua estrutura (lipídios) } \\
\text { - Os polímeros podem driblar a formação de } \\
\text { proteína corona, além de impedirem a fagocitose } \\
\text { inespecífica } \\
\text { - São mais baratas e biocompatíveis }\end{array}$ \\
\hline Desvantagens & $\begin{array}{l}\text { - Podem causar citotoxicidade } \\
\text { celular } \\
\text { - Normalmente apresentam efeitos } \\
\text { neurotóxicos ou nefrotóxicos } \\
\text { - Em sua fabricação, são utilizados } \\
\text { alguns compostos tóxicos para o } \\
\text { meio ambiente }\end{array}$ & $\begin{array}{l}\text { - Os lipídios podem sofrer ação enzimática mais } \\
\text { cedo e não serem absorvidos pela célula tumoral }\end{array}$ \\
\hline
\end{tabular}

O PLA possui eficiente retenção tumoral a partir da vetorização passiva em sistemas in vivo e é muito associado a outros polímeros, como o PEG, na forma combinada de MPEG-PLA ${ }^{50}$.

O PEG é outro polímero biodegradável com propriedades que favorecem sua utilização como um bom carreador. O PEG é, muitas vezes, manipulado associado com outras moléculas, ou simplesmente como polímero revestidor de $\mathrm{NP}^{51}$. Tem como principal função tornar as NP revestidas por ele não perceptíveis ao sistema imunológico e às células do sistema retículo endotelial $(\mathrm{RES})^{52}$, por bloquear a inserçáo de proteína corona em suas superfícies ${ }^{49}$, prolongando a circulação sistêmica das NP no organismo ${ }^{53}$. PEG e PLA (PEG-PLA) são comumente encontrados associados como excelentes carreadores de moléculas. Sua conformação é anfipática, podendo ser administrada em meio aquoso ou lipídico após administração intravenosa ${ }^{50}$.

No estudo apresentado por Xiang et al..$^{54}$, NP de PEG em associação foram utilizadas para carrear doxorrubicina contra células de hepatocarcinoma. Os autores observaram que, nas primeiras 24 horas, a viabilidade celular cancerígena reduziu em $40 \%$, comparada com a cultura controle em diferentes concentraçôes dessa conjugação.

PLA e PEG também podem ser usados como carreadores de moléculas, como miRNA, conforme demonstrado no experimento de Devulapally et al. ${ }^{55}$. O Quadro 2 mostra o resumo das principais NP abordadas e suas utilizaçóes gerais que encapsularam miRNA supressor de proteína e a droga gentamicina contra células de hepatocarcinoma em NP de PLA.

Eles observaram que a viabilidade celular do tumor foi reduzida em $30 \%$ à medida que o tamanho das NP aumentava ${ }^{55}$. Cosco et al..$^{56}$ também utilizaram PLA junto com quitosana para carrear RNA de interferência contra células de mieloma. As duas linhagens celulares utilizadas nesse estudo ${ }^{56}$ tiveram viabilidade celular diminuída em até $30 \%$ em 24 horas. Após as 48 horas, a viabilidade celular diminuiu em 50\%, com uma concentraçáo de 100 nm de NP de quitosana (Tabela 2).

A quitosana ou chitosan ( $\mathrm{N}$-acetil glucosamina) é um polissacarídeo polimerizado biodegradável, de

Quadro 2. Principais tipos de nanopartículas e suas funcionalidades gerais

\begin{tabular}{|c|c|c|}
\hline $\begin{array}{l}\text { Tipos de } \\
\text { nanopartículas }\end{array}$ & $\begin{array}{c}\text { Principais moléculas nanoparticuladas } \\
\text { representadas }\end{array}$ & Utilização geral \\
\hline Metálica & Platina, ferro e prata & $\begin{array}{c}\text { Potencialização de morte tumoral por } \\
\text { meio da geração de espécies reativas de } \\
\text { oxigênio; carreador de fármaco }\end{array}$ \\
\hline Polimérica & Polietilenoglicol e poliácido lático & $\begin{array}{c}\text { Revestidores de nanopartículas; carreador } \\
\text { de fármaco }\end{array}$ \\
\hline Proteica & Albumina & Carreador de fármaco \\
\hline Lipídica & Micelares, lipossomais e lipídicas & Carreador de fármaco \\
\hline
\end{tabular}


Tabela 2. Experimentos envolvendo nanopartículas de polímeros

\begin{tabular}{|c|c|c|c|c|c|c|c|}
\hline Autor/ano & $\begin{array}{l}\text { Polímero } \\
\text { utilizado }\end{array}$ & $\begin{array}{l}\text { Molécula } \\
\text { carreada }\end{array}$ & $\begin{array}{l}\text { In vivo/ } \\
\text { in vitro }\end{array}$ & $\begin{array}{l}\text { Tipo de } \\
\text { célula } \\
\text { tumoral }\end{array}$ & Linhagem & $\begin{array}{c}\text { Concentração } \\
\mu \mathrm{g} / \mathrm{mL}\end{array}$ & $\begin{array}{l}\text { Redução da } \\
\text { viabilidade } \\
\text { (\%) após } 48 \text { h }\end{array}$ \\
\hline $\begin{array}{l}\text { Fesehee et } \\
\text { al., } 2017\end{array}$ & PLGA & Disulfiram & In vitro & Mama & MCF-7 & $500 *$ & $80 \%$ \\
\hline $\begin{array}{l}\text { Xiang et al., } \\
2013\end{array}$ & PEG-PDLLA & $\begin{array}{l}\text { Doxorrubicina e } \\
\text { monometil éter } \\
\text { Hematoporfirina }\end{array}$ & In vitro & Fígado & HepG2 & 2 & $70 \% * *$ \\
\hline $\begin{array}{l}\text { Cao et al., } \\
2016\end{array}$ & PLGA & $\begin{array}{c}\text { Docetaxel e } \\
\text { LHRH }\end{array}$ & In vitro & Próstata & LNCaP & 10 & $80 \%$ \\
\hline $\begin{array}{l}\text { Devula-pally } \\
\text { et al., } 2016\end{array}$ & PLGA-PEG & $\begin{array}{c}\text { Gencitambina e } \\
\text { miRNA }\end{array}$ & In vitro & Fígado & HepG2 & $5^{*}$ & $60 \%$ \\
\hline $\begin{array}{l}\text { Cosco et al., } \\
2015\end{array}$ & PLGA & $m i R-34 a$ & In vitro & $\begin{array}{l}\text { Mieloma } \\
\text { múltiplo }\end{array}$ & SKMM 1 & $100 *$ & $50 \%$ \\
\hline $\begin{array}{l}\text { Wang et al., } \\
2015\end{array}$ & PLGA & $\begin{array}{l}\text { Placlitaxel e } \\
\text { Etoposídeo }\end{array}$ & In vitro & Osso & Saos-2 & 10 & $70 \%$ \\
\hline
\end{tabular}

Legenda: *A concentração é expressa em nanômetros (nm); ${ }^{* *} \mathrm{O}$ índice de diminuição se apresenta nas primeiras 24 horas.

baixa imunogenicidade e não tóxico, que também é utilizado como carreador de drogas ${ }^{57}$. Pode ser encontrado em associação tanto com PLA como PEG, carreando antineoplásicos conhecidos como cisplatina ou doxorrubicina ${ }^{58}$. Entretanto, a quitosana também apresenta desafios, como a baixa solubilidade do seu material, característicos de compostos naturais ${ }^{57,59}$.

Nos estudos de Xiang et al..$^{54}$ e Devulapally et al. ${ }^{55}$, ambos envolvendo linhagens tumorais hepáticas HepG2, podem ser observadas divergências por intermédio das moléculas carreadas e das concentraçóes envolvidas no estudo. No experimento de Xiang et al. ${ }^{54}$, a diminuiçáo da quantidade de células tumorais em $70 \%$ foi observada nas primeiras 24 horas, enquanto, no estudo de Devulapally et al..$^{55}$, somente após as 48 horas, o índice de diminuição chegou a $60 \%$, indicando que o conjugado apresentado por Xiang et al. ${ }^{54}$ apresenta maior eficiência contra células de HepG2.

Já Fasehee et al. ${ }^{60}$ observaram uma queda de $80 \%$ na viabilidade tumoral ao encapsular disulfiram, um inibidor de aldeído desidrogenase (ALDH), com moléculas de Poly(lactic-co-glycolic) acid (PLGA). Neste estudo, foram observados o disulfiram livre e o disulfiram encapsulado. No estudo de Fasehee et al. ${ }^{60}$, a inibição máxima foi obtida após as 48 horas e o efeito de citotoxicidade dobrou em relação às primeiras 24 horas. Entretanto, no estudo de Wang et al. ${ }^{61}$, não foram observados grandes efeitos citotóxicos nas 48 horas em relação às primeiras 24 horas, mesmo utilizando linhagens cancerígenas diferentes para comparação.

Não houve queda de viabilidade visível entre 24 horas e 48 horas, demonstrando que, no estudo de Wang et al. ${ }^{61}$, o principal fator limitante náo foi o encapsulamento em PLGA, mas sim as moléculas carreadas utilizadas nas linhagens tumorais.

Normalmente, o processo de produção mais utilizado na fabricação de NP é o método químico, no qual uma solução redutora de íons específica, como o $\mathrm{NaBH}_{4}$ ou o nitrato de sódio, é usada para reduzir determinado composto que contenha o material desejado. Existem outros métodos de fabricação como os radiolíticos, fotoquímicos ou biogênicos ${ }^{62}$. Em todo o processo, a administraçáo de reagentes necessita de muito cuidado, pois qualquer erro causado pelas diferenças de concentraçōes pode atrapalhar a formação de nanomoléculas ${ }^{63}$.

O problema da utilização dos muitos compostos químicos envolvidos nesse processo de fabricação é o grande índice de toxicidade que limita as aplicaçóes dessas soluçóes, além de serem relativamente caras. Diante dessa barreira, recentemente uma nova alternativa para a produção de NP tem sido abordada na nanotecnologia, a Green Technology ${ }^{64}$ ou tecnologia ambiental, voltada para a não utilização de compostos químicos na indústria. Essa nova ferramenta, além de não utilizar substâncias tóxicas para o meio ambiente, é mais barata e pode usar como matéria-prima plantas, bactérias ou compostos proteicos ${ }^{9,65}$.

Extratos de plantas e frutas são usados para substituírem a oxidorredução de compostos químicos e podem ser estabilizantes ou até promover, dependendo do extrato utilizado, atividade biológica sem causar danos ao organismo ${ }^{66}$. As NP de ouro, conforme demonstrado no experimento de Bahahara et al. ${ }^{28}$, foram construídas por uma planta de origem indiana, a Zataria multiflora, utilizada como redutor do metal. Apesar dos benefícios da Green Technology, a sua utilização nos laboratórios 
científicos ainda se encontra distante, por conta da falta conhecimento e de instrução na utilização dessa técnica ${ }^{65}$.

Além da Green Technology, outras aplicabilidades vêm surgindo ao longo dos anos envolvendo NP no tratamento do câncer, como, por exemplo, a fototerapia e a terapia fototermal. A fototerapia é uma combinação direta com quimioterápicos, na qual fotossensibilizadores são acionados a partir de uma fonte de irradiação, tornando-se uma vertente de aplicação mais segura e específica, já que as NP serão ativadas na regiáo do corpo onde a luz for concentrada ${ }^{67}$.

Já na terapia fototermal, as NP são acionadas a partir de uma fonte de calor, que normalmente é a luz infravermelha, na qual se aplicam ondas de pequeno ou grande comprimento. Após a ativaçáo por meio do calor, a NP já absorvida na célula é desintegrada pelo calor, causando necrose à célula tumoral. Normalmente, as NP à base de carbono são usadas nesse procedimento ${ }^{68}$.

Outro tipo de aplicação recente com NP é a terapia gênica. Nessa terapia, pequenas moléculas que podem interferir ou alterar a estrutura de DNA são incorporadas no interior das NP, como plasmídeos de DNA, miRNA ou RNA de interferência ${ }^{67}$, como mostrado nos estudos de Devulapally et al. ${ }^{55}$ e Xiang et al..$^{54}$ Terapias que utilizam genes interferentes e quimioterapia são favoráveis para a erradicação de tumores, mas enfrentam desafios como a estrutura pequena de seus materiais não alcançando efeitos consideráveis ${ }^{67}$. Os vírus também estão sendo estudados como novos agentes carreadores de drogas, por conterem características biocompatíveis com o corpo humano, facilidade de molde em vários tamanhos e formas, podendo ser conjugado junto com PEG para prolongar seu tempo na corrente sanguínea.

Alguns tratamentos já conhecidos como a radioterapia e a quimiorradioterapia estão adotando o uso de NP. No estudo de Au et al. ${ }^{69}$, a wortmanina foi conjugada junto ao docetaxel em NP de PEG-PLA, apresentando um volume tumoral abaixo de $10 \%$ em um período de 120 dias. Compostos inorgânicos também apresentam ótima absorção de radiação, sendo bons materiais para serem usados em radioterapia ${ }^{70}$.

\section{CONCLUSÃO}

A descoberta da nanotecnologia no campo médico proporcionou a utilização de terapias anticancerígenas que anteriormente teriam alto índice de toxicidade para o corpo humano, em razão da possibilidade de redução de efeitos adversos citotóxicos causados pela não especificidade da terapia convencional. Ao passar dos anos, as técnicas envolvendo fabricação e aplicaçóes com NP evoluíram, proporcionando uma melhor eficiência na entrega de fármacos e o direcionamento sítio-específico. Além das NP metálicas já conhecidas pela comunidade científica, outras moléculas ganharam espaço com a busca de meios mais limpos de produçáo e não toxicidade como as NP à base de polímeros, proteínas e lipídios, que protagonizam o novo cenário de quimioterapia com NP, sendo responsáveis por introduzir fármacos importantes ao combate tumoral.

Concluiu-se que, com suas propriedades químicas variadas e seus mecanismos de geração de ERO, algumas NP apresentam efeitos tóxicos contra células tumorais diferentes, independente de carrearem ou não algum fármaco, podendo apresentar um efeito antitumoral mais eficaz em determinadas linhagens tumorais que apontam suscetibilidade celular para aquele tipo de NP ou fármaco carreado. Apesar dos bons resultados envolvendo NP e antineoplásicos, obstáculos como fagocitose inespecífica e efeitos adversos causados pela toxicidade da fabricação precisam ser mais bem discutidos e estudados.

\section{CONTRIBUIÇÕES}

Ambas as autoras contribuíram igualmente na concepção, planejamento do estudo, obtenção, análise e interpretação dos dados, assim como na redação e/ou revisão crítica e aprovação final da versão publicada.

\section{DECLARAÇÃO DE CONFLITO DE INTERESSES}

Nada a declarar.

\section{FONTES DE FINANCIAMENTO}

Não há.

\section{REFERÊNCIAS}

1. Bea DB, Tejeda AP, Pardo AA, et al. Nanomedicine: general aspects of a promissory future. $\mathrm{R} \quad \mathrm{e} \quad \mathrm{v}$ Habanera Cienc Méd. 2011;10(3):410-21.

2. Disner GR, Cestari MM. Nanociência e nanotecnologia. Evidência. 2016;16(1):71-6. doi: https://doi. org/10.18593/eba.v16i1.10660

3. Khan I, Saeed K, Khan I. Nanoparticles: properties, applications and toxicities. Arabian J Chemistry. 2019. 12(7):908-31. doi: https://doi.org/10.1016/j. arabjc.2017.05.011

4. Zhang P, Wang P, Yan L, et al. Synthesis of gold nanoparticles with Solanum xanthocarpum extract and their in vitro anticancer potential on nasopharyngeal carcinoma cells. Int J Nanomedicine. 2018;13:7047-59. doi: https://doi.org/10.2147/IJN.S180138

5. Fang RH, Kroll AV, Zhang L. Nanoparticle-based 
manipulation of antigen-presenting cells for cancer immunotherapy. Small. 2015;11(41):5483-96. doi: https://doi.org/10.1002/smll.201501284

6. Asai T. Nanoparticle-mediated delivery of anticancer agents to tumor angiogenic vessels. Biol Pharm Bull. 2012;35(1):11:1855-61. doi: https://doi.org/10.1248/ bpb.b212013

7. Tang L, Yang X, Yin Q, et al. Investigating the optimal size of anticancer nanomedicine. PNAS. 2014;111(43):15344-9. doi: https://doi.org/10.1073/ pnas. 1411499111

8. Din FU, Aman W, Ullah I, et al. Effective use of nanocarriers as drug delivery systems for the treatment of selected tumors. Int J Nanomedicine. 2017;12:72917309. doi: https://doi.org/10.2147/IJN.S146315

9. Vieira DB, Gamarra LF. Avanços na utilização de nanocarreadores no tratamento e no diagnóstico de câncer. Einstein. 2016; 14(1):99-103. doi: https://doi. org/10.1590/S1679-45082016RB3475

10. Oliveira LC, Taveira EJF, Souza LG, et al. Aplicaçóes das nanopartículas lipídicas no tratamento de tumores sólidos: revisão de literatura. Rev Bras Cancerol. 2012;58(4):695-701. doi: https://doi. org/10.32635/2176-9745.RBC.2012v58n4.581

11. Golan DE. Princípios de farmacologia antimicrobiana e antineoplásica. In: Golan DE, Tashjian AH, Armstrong EJ, et al. Princípios de farmacologia: a base fisiopatológica da farmacologia. 3. ed. Rio de Janeiro: Guanabara Koogan; 2009. Cap. 32, p. 572.

12. Zhang S, Gao H, Bao G. Physical principles of nanoparticle cellular endocytosis. ACS Nano. 2015;9(9):8655-71. doi: https://doi.org/10.1021/ acsnano. 5 b03184

13. Vilar-Alvarez E, Cambón A, Pardo A, et al. Gold nanorod-based nanohybrids for combinatorial therapeutics. ACS Omega. 2018;3:12633-47. doi: https://doi.org/10.1021/acsomega.8b01591

14. Jurj A, Braicu C, Pop LA, et al. The new era of nanotechnology, an alternative to change cancer treatment. Drug Des Devel Ther. 2017;11:2871-90. doi: https://doi.org/10.2147/DDDT.S142337

15. Khan M, Khan M, Al-Marrari AH, et al. Apoptosis inducing ability of silver decorated highly reduced graphene oxide nanocomposites in A549 lung cancer. Int J Nanomedicine. 2016:11:873-83. doi: https://doi. org/10.2147/IJN.S100903

16. Bai DP, Zhang XF, Zhang, GL, et al. Zinc oxide nanoparticles induce apoptosis and autophagy in human ovarian cancer cells. Int J Nanomedicine. 2017:12:6521-35. doi: https://doi.org/10.2147/IJN. S140071

17. Bisht $\mathrm{G}$, Rayamajhi S. ZnO nanoparticles: a promising anticancer agent. Nanobiomedicine (Rij). 2016;3:9:111. doi: https://doi.org/10.5772/63437
18. M JF, P L. Apoptotic efficacy of biogenic silver nanoparticles on human breast cancer MCF-7 cell lines. Prog Biomarter. 2015;4:113-21. doi: https://doi. org/10.1007/s40204-015-0042-2

19. Han JW, Gurunathan S, Choi YJ, et al. Dual functions of silver nanoparticles in F9 teratocarcinoma stem cells, a suitable model for evaluating cytotoxicityand differentiation-mediated cancer therapy. Int J Nanomedicine. 2017;12:7529-49. doi: https://doi. org/10.2147/IJN.S145147

20. Choi YJ, Park JH, Han JW, et al. Differential cytotoxic potential of silver nanoparticles in human ovarian cancer cells and ovarian cancer stem cells. Int J Mol Sci. 2016;17(12):2077. doi: https://doi.org/10.3390/ ijms 17122077

21. Wang J, Gao S, Wang S, et al. Zinc oxide nanoparticles induce toxicity in CAL 27 oral cancer cell lines by activating PINK1/Parkin-mediated mitophagy. Int J Nanomedicine. 2018:13:3441-50. doi: https://doi. org/10.2147/IJN.S165699

22. Rasmussen JW, Martinez E, Louka P, et al Zinc oxide nanoparticles for selective destruction of tumor cells and potential for drug delivery applications. Expert Opin Drug Deliv. 2010;7(9):1063-77. doi: https://doi.org/ $10.1517 / 17425247.2010 .502560$

23. Chung M, Rahuman AA, Marimuthu S, et al. An investigation of the cytotoxicity and caspase-mediated apoptotic effect of green synthesized zinc oxide nanoparticles using Eclipta prostrata on human liver carcinoma Cells. Nanomaterials. 2015;5(3):1317-30. doi: https://doi.org/10.3390/nano5031317

24. Chakraborty B, Pal R, Ali M, et al. Immunomodulatory properties of silver nanoparticles contribute to anticancer strategy for murine fibrosarcoma. Cell Mol Immunol. 2016;13(2):191-205. doi: https://doi. org/10.1038/cmi.2015.05

25. Gurunathan S, Park JH, Han JW, et al. Comparative assessment of the apoptotic potential of silver nanoparticles synthesized by Bacillus tequilensis and Calocybe indica in MDA-MB-231 human breast cancer cells: targeting p53 for anticancer therapy. Int J Nanomedicine. 2015;10:4203-23. doi: https://doi. org/10.2147/IJN.S83953

26. Bhanumathi R, Manivannan M, Thangaraj R, et al. Drug-carrying capacity and anticancer effect of the folic acid- and berberine-loaded silver nanomaterial to regulate the akt-erk pathway in breast cancer. ACS omega 2018;3(7):8317-28. doi: https://doi. org/10.1021/acsomega.7b01347

27. Lee MJ, Lee SJ, Yun SJ, et al. Silver nanoparticles affect glucose metabolism in hepatoma cells through production of reactive oxygen species. Int J Nanomedicine. 2016;11:55-68. doi: https://doi. org/10.2147/IJN.S94907 
28. Bahahara J, Ramezani T, Hosseini N, et al. Silver nanoparticles synthesized coating with zataria multiflora leaves extract induced apoptosis in HeLa cells through p53 activation. Iran J Pharm Res. 2018;17(2):627-39. doi: https://doi.org/10.22037/IJPR.2018.2191

29. He Y, Du Z, Ma S, et al. Effects of green-synthesized silver nanoparticles on lung cancer cells in vitro and grown as xenograft tumors in vivo. Int J Nanomedicine. 2016;11:1879-87. doi: https://doi.org/10.2147/IJN. S103695

30. Wang T, Yang S, Mei LA, et al. Paclitaxel-loaded PEG-PE-based micellar nanopreparations targeted with tumor-specific landscape phage fusion protein enhance apoptosis and efficiently reduce tumors. Mol Cancer Ther. 2014;13(12):2864-75. doi: https://doi. org/10.1158/1535-7163.MCT-14-0052

31. Arooj A, Nazir S, Nadhman A, et al. Novel ZnO:Ag nanocomposites induce significant oxidative stress in human fibroblast malignant melanoma (Ht144) cells. Beilstein J Nanotechnol. 2015;6:570-82. doi: https:// doi.org/10.3762/bjnano.6.59

32. Rokade SS, Joshi KA, Mahajan K, et al. Gloriosa superba mediated synthesis of platinum and palladium nanoparticles for induction of apoptosis in breast cancer. Bioinorg Chem Appl. 2018;2018: 4924186. doi: https://doi.org/10.1155/2018/4924186

33. Sadhukha T, Prabha S. Encapsulation in nanoparticles improves anti-cancer efficacy of carboplatin. AAPS PharmSciTech. 2014;15(4):1029-38. doi: https://doi. org/10.1208/s12249-014-0139-2

34. Leite EA, Souza CM, Carvalho-Junior AD, et al. Encapsulation of cisplatin in long-circulating and $\mathrm{pH}$-sensitive liposomes improves its antitumor effect and reduces acute toxicity. Int J Nanomedicine. 2012;7:5259-69. doi: https://doi.org/10.2147/IJN. S34652

35. Haririan I, Alavidjeh MS, Khorramizadeh MR, et al. Anionic linear-globular dendrimer-cis-platinum (II) conjugates promote cytotoxicity in vitro against different cancer cell lines. Int J Nanomedicine. 2010;5:63-75. doi: https://doi.org/10.2147/IJN.S8595

36. Guven A, Rusakova IA, Lewis MT, et al. Cisplatin@ustube carbon nanocapsules for enhanced chemotherapeutic delivery. Biomaterials. 2012;33(5):1455-61. doi: https://doi.org/10.1016/j.biomaterials.2011.10.060

37. Bendale Y, Bendale V, Paul S. Evaluation of cytotoxic activity of platinum nanoparticles against normal and cancer cells and its anticancer potential through induction of apoptosis. Integr Med Res. 2017;6(2):1418. doi: https://doi.org/10.1016/j.imr.2017.01.006

38. Oberoi HS, Nukolova NV, Kabanov AV, et al. Nanocarriers for delivery of platinum anticancer drugs. Adv Drug Deliv Rev. 2013;65(13-14):1667-85. doi: https://doi.org/10.1016/j.addr.2013.09.014
39. Lohcharoenkal W, Wang L, Chen YC, et al. Protein nanoparticles as drug delivery carriers for cancer therapy. Biomed Res Int. 2014:180549. doi: https:// doi.org/10.1155/2014/180549

40. Noorani L, Stenzel M, Liang R, et al. Albumin nanoparticles increase the anticâncer efficacy of albendazole in ovarian câncer xenograft model. J Nanobiotechnology. 2015;13:25. doi: https://doi. org/10.1186/s12951-015-0082-8

41. Azizi M, Ghourchian H, Yazdian F, et al. Anti-cancerous effect of albumin coated silver nanoparticles on MDAMB 231 human breast cancer cell line. Scientific Reports. 2017;7:5178. doi: https://doi.org/10.1038/ s41598-017-05461-3

42. Lee JE, Kim MG, Jang YL, et al. Self-assembled PEGylated albumin nanoparticles (SPAN) as a platform for cancer chemotherapy and imaging. Drug Deliv. 2018;25(1):1570-78. doi: https://doi.org/10.1080/10 717544.2018 .1489430

43. Badawy AA, El-Magd MA, AlSadrah SA. Therapeutic effect of camel milk and its exosomes on MCF7 cells in vitro and in vivo. Integr Cancer Ther. 2018;17(14):123546. doi: https://doi.org/10.1177/1534735418786000

44. Huang R, Li J, Kebebe D, et al. Cell penetrating peptides functionalized gambogic acid-nanostructured lipid carrier for cancer treatment. Drug Deliv. 2018;25(1):757-65. doi: https://doi.org/10.1080/107 17544.2018.1446474

45. Cho H, Lai TC, Tomoda K, et al. Polymeric micelles for multi-drug delivery in cancer. AAPS PharmSciTech. 2015;16(1):10-20. doi: https://doi.org/10.1208/ s12249-014-0251-3

46. Selvamuthukumar S, Velmurugan R. Nanostructured lipid carriers: a potential drug carrier for cancer chemotherapy. Lipids Health Dis. 2012;11:159. doi: https://doi.org/10.1186/1476-511X-11-159

47. Silva MC, Oliveira SV, Araújo EM. Propriedades mecânicas e térmicas de sistemas de PLA e PBAT/ PLA. Revista Eletrônica de Materiais e Processos. 2014;9(2):112-117.

48. Bao W, Liu R, Wang Y, et al. PLGA-PLL-PEG-Tf-based targeted nanoparticles drug delivery system enhance antitumor efficacy via intrinsic apoptosis pathway. Int J Nanomedicine. 2015;10:557-66. doi: https://doi. org/10.2147/IJN.S75090

49. Mirakabad FST, Nejati-Koshki K, Akbarzadeh A, et al. PLGA-based nanoparticles as cancer drug delivery systems. Asian Pac J Cancer Prev. 2014;15(2):517-35. doi: https://doi.org/10.7314/APJCP.2014.15.2.517

50. Zheng W, Li M, Lin Y, et al. Encapsulation of verapamil and doxorubicin by MPEG-PLA to reverse drug resistance in ovarian cancer. Biomed Pharmacother. 2018;108:565-73. doi: https://doi.org/10.1016/j. biopha.2018.09.039 
51. Zheng S, Li X, Zhang Y, et al. PEG-nanolized ultrasmall selenium nanoparticles overcome drug resistance in hepatocellular carcinoma HepG2 cells through induction of mitochondria dysfunction. Int J Nanomedicine. 2012;7:3939-49. doi: https://doi. org/10.2147/IJN.S30940

52. Cao LB; Zeng S, Zhao W. Highly Stable PEGylated Poly(lactic-co-glycolic acid) (PLGA) nanoparticles for the effective delivery of docetaxel in prostate cancers. Nanoscale Res Lett. 2016;11(1):305. doi: https://doi. org/10.1186/s11671-016-1509-3

53. Udofot O, Affram K, Smith T, et al. Pharmacokinetic, biodistribution and therapeutic efficacy of 5-fluorouracilloaded $\mathrm{pH}$-sensitive PEGylated liposomal nanoparticles in HCT-116 tumor bearing mouse. J Nat Sci. 2016;2(1):e171.

54. Xiang GH, Hong G, Wang Y, et al. Effect of PEGPDLLA polymeric nanovesicles loaded with doxorubicin and hematoporphyrin monomethyl ether on human hepatocellular carcinoma HepG2 cells in vitro. Int J Nanomedicine. 2013;8(1):4613-22. doi: https://doi. org/10.2147/IJN.S54142

55. Devulapally R, Foygel K, Sekar TV, et al. Gemcitabine and antisense-microRNA co-encapsulated PLGA-PEG polymer nanoparticles for hepatocellular carcinoma therapy. ACS Appl Mater Interfaces. 2016;8(49):3341222. doi: https://doi.org/10.1021/acsami.6b08153

56. Cosco D, Cilurzo F, Maiuolo J, et al. Delivery of miR34 a by chitosan/PLGA nanoplexes for the anticancer treatment of multiple myeloma. Sci Rep. 2015;5:17579. doi: https://doi.org/10.1038/srep17579

57. Wei X, Liao J, Davoudi Z, et al. Folate receptortargeted and GSH-responsive carboxymethyl chitosan nanoparticles containing covalently entrapped 6-mercaptopurine for enhanced intracellular drug delivery in leukemia. Mar Drugs. 2018;16(11):439. doi: https://doi.org/10.3390/md16110439

58. Xu Q, Leong J, Chua QY, et al. Combined modality doxorubicin-based chemotherapy and chitosan-mediated p53 gene therapy using double-walled microspheres for treatment of human hepatocellular carcinoma. Biomaterials. 2013;34(21):5149-62. doi: https://doi. org/10.1016/j.biomaterials.2013.03.044

59. Andima M, Costabile G, Isert L, et al. Evaluation of $\beta$-sitosterol loaded PLGA and PEG-PLA nanoparticles for effective treatment of breast cancer: preparation, physicochemical characterization, and antitumor activity. Pharmaceutics. 2018;10(4):232. doi: https:// doi.org/10.3390/pharmaceutics 10040232

60. Fasehee H, Ghavamzadeh A, Alimoghaddam K, et al. A comparative cytotoxic evaluation of disulfiram encapsulated PLGA nanoparticles on MCF-7 cells. Int J Hematol Oncol Stem Cell Res. 2017;11(2):102-7.
61. Wang B, Yu XC, Xu SF, et al. Paclitaxel and etoposide co-loaded polymeric nanoparticles for the effective combination therapy against human osteosarcoma. J Nanobiotechnology. 2015;13:22. doi: https://doi. org/10.1186/s12951-015-0086-4

62. Souto EB, Severino P, Santana MHA. Preparação de nanopartículas poliméricas a partir de polímeros préformados: parte II. Polímeros. 2012;22(1):101-6. doi: https://doi.org/10.1590/S0104-14282012005000005

63. Junior MAM, Santos LSS, Gonçalves MC, Nogueira AF. Preparação de nanopartículas de prata e ouro: um método simples para a introdução da nanociência em laboratório de ensino. Quim Nova. 2012;35(9):1872-78. doi: https://doi.org/10.1590/S0100-4042201200090003

64. Lalitha A, Subbaiya R, Ponmurugan P. Green synthesis of silver nanoparticles from leaf extract Azhadirachta indica and to study its anti-bacterial and antioxidant property. Int J Curr Microbiol App Sci [Internet]. 2013 [cited 2018 July 13];2(6):228-35. Available from: https://pdfs.semanticscholar.org/d811/ bdb6b1ff1f9c98a63249408fee6ac36d6baf.pdf

65. Rani K, Sridevi V. An overview on role of nanotechnology in green and clean technology. Austin Environ Sci. 2017;2(3):1026. doi: https://doi.org/10.26420/ austinenvironsci.2017.1026

66. Ivashchenko O, Przysiecka L, Poplinska B, et al. Gel with silver and ultrasmall iron oxide nanoparticles produced with Amanita muscaria extract: physicochemical characterization, microstructure analysis and anticancer properties. Scientific Reports. 2018;8:13260. doi: https://doi.org/10.1038/s41598-018-31686-x

67. Meng F, Han N, Yeo Y. Organic nanoparticle systems for spatiotemporal control of multimodal chemotherapy. Expert Opin Drug Deliv. 2017;14(13):427-46. doi: https://doi.org/10.1080/17425247.2016.1218464

68. Machado IRL, Mendes HMF, Alves GES, et al. Nanotubos de carbono: potencial de uso em medicina veterinária. Cienc Rural. 2014;44(10):1823-29. doi: https://doi.org/10.1590/0103-8478cr20140003

69. Au KM, Min Y, Tian X, et al. Improving cancer chemoradiotherapy treatment by dual controlled release of wortmannin and docetaxel in polymeric nanoparticles. ACS Nano. 2015;9(9):8976-96. doi: https://doi.org/10.1021/acsnano.5b02913

70. Casals E, Gusta MF, Siles MC, et al. Cancer resistance to treatment and antiresistance tools offered by multimodal multifunctional nanoparticles. Cancer Nanotechnol. 2017;8(1):7. doi: https://doi.org/10.1186/s12645$017-0030-4$ 